\title{
Local recurrence of sclerosing mucoepidermoid carcinoma with eosinophilia in the upper lip: a case report
}

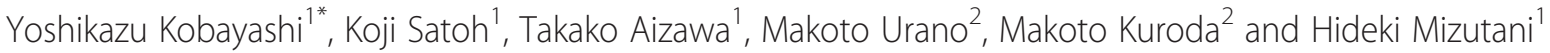

\begin{abstract}
Introduction: Sclerosing mucoepidermoid carcinoma with eosinophilia is a rare morphological variant of thyroid carcinoma associated with Hashimoto's disease. To date, only three such tumors have been reported in the minor salivary glands. We describe the first case, to the best of our knowledge, of recurrent sclerosing mucoepidermoid carcinoma with eosinophilia in the minor salivary glands of the upper lip.
\end{abstract}

Case presentation: A 61-year-old Japanese man was referred to our hospital with a mass in his median upper lip of four years' duration. An examination of his median upper lip revealed a well-defined tumor measuring $9 \times 12 \mathrm{~mm}$ in diameter, which was subsequently resected. Three years after the first surgery, the tumor recurred and was resected. Both tumors were confirmed by histopathology to be sclerosing mucoepidermoid carcinoma with eosinophilia. Neither recurrence nor metastasis was observed in three and a half years of follow-up after the second surgery.

Conclusion: Our findings indicate that sclerosing mucoepidermoid carcinoma with eosinophilia can originate in the minor salivary glands and may be clinically or pathologically misdiagnosed as other conditions.

Keywords: Lip cancer, Minor salivary glands, Sclerosing mucoepidermoid carcinoma, Tissue eosinophilia

\section{Introduction}

In 1991, sclerosing mucoepidermoid carcinoma with eosinophilia (SMECE) was proposed to be a rare morphological variant of thyroid carcinoma associated with Hashimoto's disease [1]. Approximately 30 cases involving the thyroid have been reported in the literature. Similar to thyroid lesions, SMECE occurring in the salivary glands generally has a lower malignancy and better prognosis than conventional mucoepidermoid carcinoma (MEC). To date, only three of these tumors have been reported in the minor salivary glands. Here, we report the case of a 61-year-old Japanese man with recurrent SMECE in his median upper lip and present a review of the relevant literature.

\section{Case presentation}

A 61-year-old Japanese man was referred to our hospital with a mass in his median upper lip of four years'

\footnotetext{
*Correspondence: y.kobayashi.oms@gmail.com

'Department of Oral and Maxillofacial Surgery, Fujita Health University School of Medicine, 1-98 Dengakugakubo, Kutsukake, Toyoake, Aichi Pref, Japan Full list of author information is available at the end of the article
}

duration. He had received interferon-ribavirin combination therapy for chronic hepatitis $\mathrm{C}$ several years earlier. He had no history of any other illness.

Our patient was aware of the mass, which had slowly grown over several years with occasional epithelial detachment or bleeding; however, he never sought treatment. The tumor was located in his median upper lip, was well-defined, measured $9 \times 12 \mathrm{~mm}$ in diameter, and was elastic, hard and ulcerated (Figure 1). Regional lymph nodes were not palpable.

The tumor appeared to be benign from its appearance and growth rate and was resected under local anesthesia. Preoperative imaging such as computed tomography (CT) or magnetic resonance imaging was not performed because the boundary of the lesion was clear. The tumor surface was smooth and covered with a capsule-like structure, and its cut surface was solid and pale yellow. We assumed that it was a benign tumor such as an atheroma or pleomorphic adenoma.

Beneath the erosive epithelium, small neoplastic nests surrounded by markedly hyperplastic fibrous connective tissue had formed. The tumor cells had pale eosinophilic 


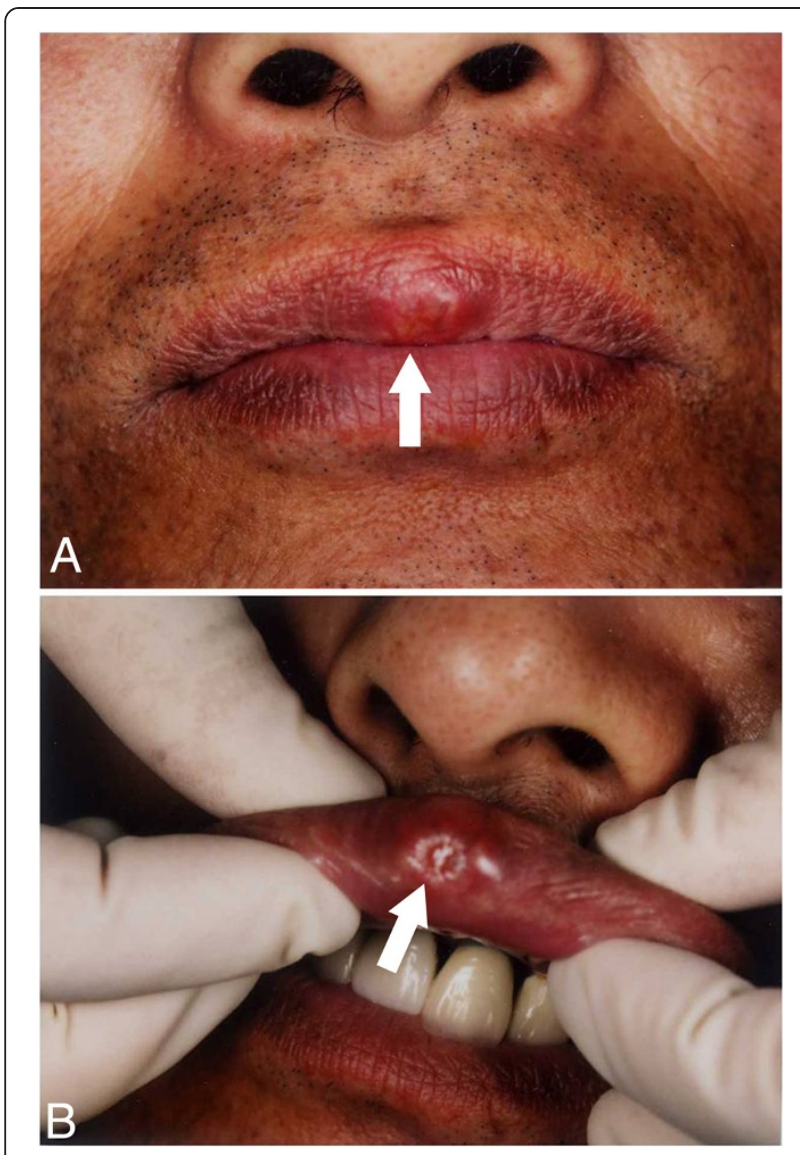

Figure 1 Gross appearance of the primary tumor. (A) The tumor was located in the median upper lip, was well-defined, measured $9 \times 12 \mathrm{~mm}$ in diameter, and was elastic and hard. (B) Partial ulceration of the mucous membrane was evident.

cytoplasm and round nuclei that included small nucleoli (Figure 2). We also observed eosinophil-rich infiltrates in the tumor nests, tubular structures containing periodic acid-Schiff-positive mucus in the lumen, goblet cells, and venous invasion (Figure 3 ). The specimen was lined by normal muscular tissue.

We performed immunostaining of the resected specimen. The ductal structure was positive for epithelial membrane antigen (EMA) and carcinoembryonic antigen (CEA), and the solid structure was positive for cytokeratin. The mindbomb E3 ubiquitin protein ligase 1 (MIB-1)-positivity rate was $7.9 \%$. There was no histological capsule; the macroscopic capsule-like structure observed may have been connective tissue covering the margin of the resected specimen.

On histopathology, the tumor was diagnosed as SMECE originating from the minor salivary glands of the lip. Based on its MIB-1-positivity rate, we designated the malignancy of the tumor as intermediate. On microscopy, the tumor nests were close to the surgical margin: $1 \mathrm{~mm}$ at the nearest point. However, additional

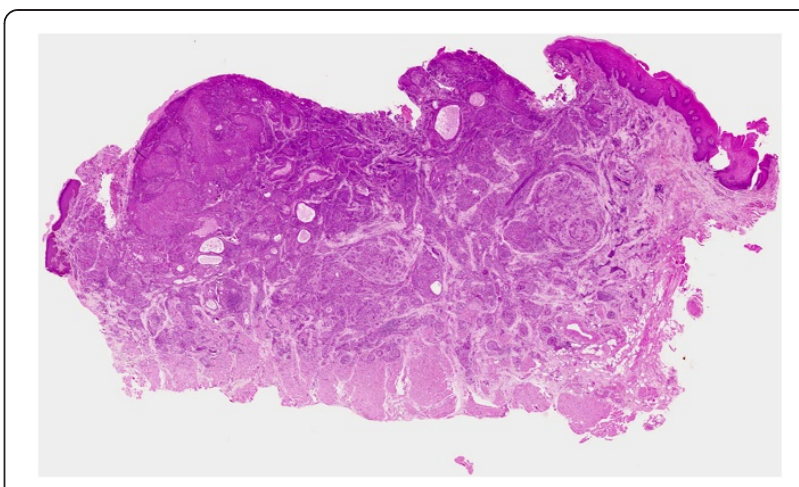

Figure 2 Macroscopic view of the primary tumor (hematoxylin and eosin staining). Small neoplastic nests surrounded by markedly hyperplastic fibrous connective tissue were evident. The lining of this specimen consisted of normal muscular tissue.

surgery was not performed at our patient's request. We performed contrast-enhanced CT of his neck and scintigraphy of his whole body, neither of which revealed any metastases. Considering the potential for metastasis from the thyroid gland or autoimmune disease, blood tests were also performed. He had no abnormalities in his thyroid hormone levels (tri-iodothyronine, thyroxin and thyroid-stimulating hormone), autoantibody levels (antinuclear antibody, anti-Sjögren's syndrome antigens A and B), or whole-blood eosinophil count. Nevertheless, we closely monitored our patient, with regular check-ups every three months and contrast-enhanced CT imaging of his cervical region once every year.

Three years after the first resection, a mass measuring $2 \mathrm{~mm}$ in diameter was detected in the same region. Local recurrence was suspected, and the tumor was resected with a $5 \mathrm{~mm}$ safety margin. Again, the resected specimen was diagnosed on histopathology as SMECE. Its histologic features were similar to those of the primary tumor (Figure 4), with a lower density of fibrous connective tissue. This specimen also had tumor-free margins on histology. Its MIB-1 positivity rate was $5.8 \%$.

A physical examination and contrast-enhanced CT of his neck revealed no signs of recurrence or metastasis three and a half years after the second surgery.

\section{Discussion}

SMECE is a rare variant of thyroid carcinoma, and only approximately 30 cases have been reported to date. The tumor is a low-grade malignancy with a good prognosis [2]. In 1987, Chan and Saw [3] reported a low-grade MEC showing an unusual pattern of extensive central sclerosis in the parotid gland and termed it sclerosing MEC. In their case, tissue eosinophils were not present. Since then, 20 cases of tumors in the major salivary glands and three of tumors in the minor salivary glands have been reported [3-15]. In many of these cases, 


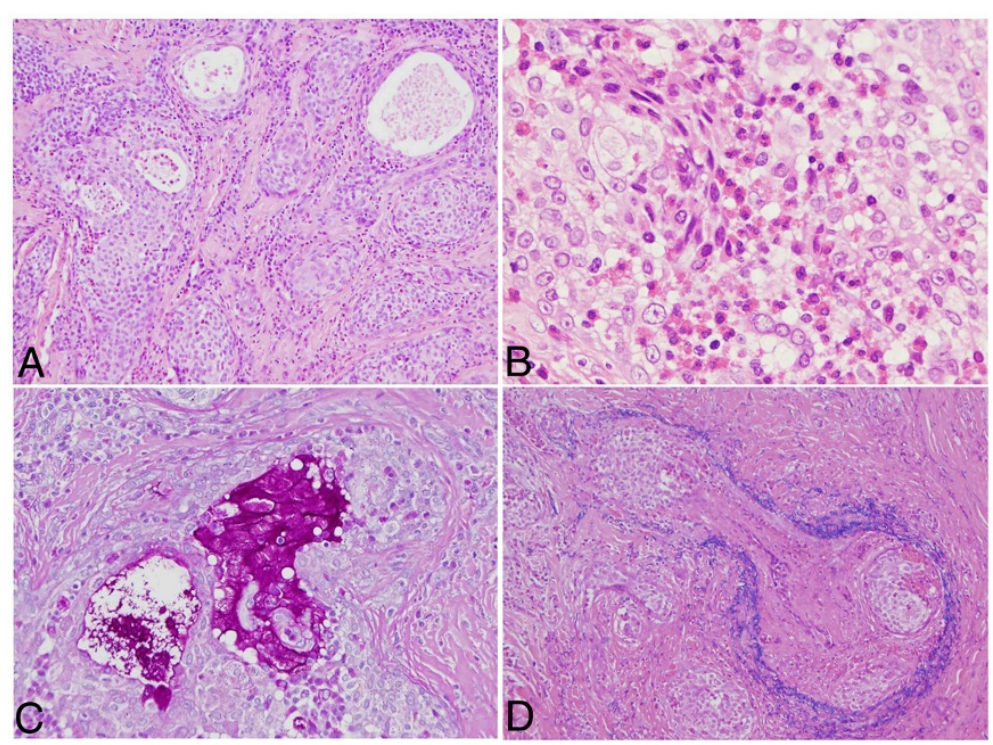

Figure 3 Histological and immunohistochemical features of the tumor. (A) Tumor nests consisted of epithelial cells and pseudoglandular structures (hematoxylin and eosin (H\&E) staining; $\times 40$ ). (B) Marked eosinophilic infiltration in the tumor stroma (H\&E; $\times 200)$. (C) The tubular structure contained periodic acid-Schiff-positive mucus in the lumen and goblet cells ( $\times 100)$. (D) Venous invasion can also be observed (Victoria blue-H\&E; $\times 100)$.

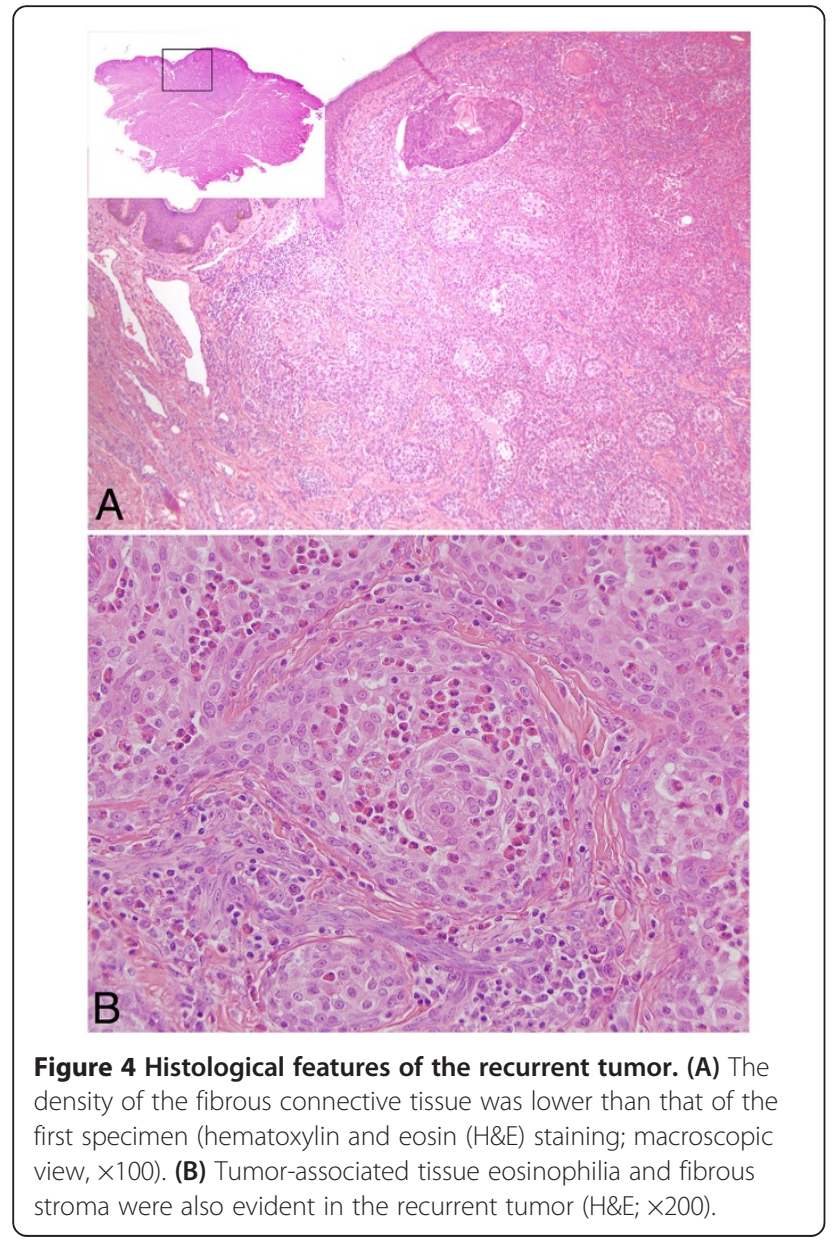

marked eosinophilic infiltration was observed (Table 1). In the latest World Health Organization classification [16], the sclerosing variant of MEC was mentioned; however, eosinophilia associated with MEC was not addressed.

On histopathology, SMECE consists of islands of cancer cells of low nuclear grade, with a sclerotic stroma heavily infiltrated by chronic inflammatory cells and eosinophils. A mixture of mucinous epithelial cells and glandular structures is also evident, and these components can merge with the squamoid islands or form discrete tubules [17].

Differential diagnoses of our case would include squamous cell carcinoma, adenosquamous cell carcinoma, low-grade cribriform cystadenocarcinoma and microcystic adnexal carcinoma. Immunostaining for markers such as EMA and CEA was useful for diagnosis. We designated the malignancy of the first resected tumor as intermediate on the basis of venous invasion and the MIB-1-positivity rate.

From an epidemiological perspective, previous reports of SMECE in the salivary glands have described its features as similar to those of ordinary MEC, with more frequent occurrence in women (16 of 24 reported cases, including ours), a wide age distribution (16 to 79 years) and predominant occurrence in the parotid glands (17 cases).

To the best of our knowledge, this is the first case of SMECE in the minor salivary glands of the lip; it is also the first case of local recurrence. Most reported cases had a good therapeutic outcome, although one patient 
Table 1 Past reports of sclerosing mucoepidermoid carcinoma

\begin{tabular}{|c|c|c|c|c|c|c|c|c|}
\hline Source & $\begin{array}{l}\text { Age } \\
\text { (years) }\end{array}$ & Gender & Site & Size $(\mathrm{cm})$ & Grade & Treatment & Follow-up & TATE \\
\hline Chan and Saw [3] & 36 & $\mathrm{~F}$ & Parotid gland & $6 \times 3 \times 2$ & Low & Superficial parotidectomy & NA & - \\
\hline Muller et al. [4] & 17 & $\mathrm{~F}$ & Parotid gland & 2 & Intermediate & Total parotidectomy & NA & + \\
\hline Muller et al. [4] & 60 & $\mathrm{~F}$ & Parotid gland & $4.5 \times 4$ & Intermediate & Resection + RT & NA & + \\
\hline Sinha et al. [5] & 65 & M & $\begin{array}{l}\text { Minor salivary glands } \\
\text { (parapharyngeal space) }\end{array}$ & $5 \times 4 \times 3$ & High & Resection +RT & NA & - \\
\hline Urano et al. [6] & 57 & $\mathrm{~F}$ & Parotid gland & $2.5 \times 2$ & Low & Superficial parotidectomy & $\begin{array}{l}\text { Lymph node } \\
\text { metastasis/3y }\end{array}$ & + \\
\hline Urano et al. [6] & 43 & M & Submandibular gland & $4.5 \times 2.5$ & Low & $\begin{array}{l}\text { Total excision of } \\
\text { submandibular gland }\end{array}$ & Dead of disease/7y & + \\
\hline Fadare et al. [7] & 44 & $\mathrm{~F}$ & Parotid gland & $4 \times 2$ & Low & Total parotidectomy + RT & NED/7y & - \\
\hline Ide et al. [8] & 28 & M & $\begin{array}{l}\text { Minor salivary glands } \\
\text { (retromolar pad) }\end{array}$ & $2 \times 2$ & Intermediate & Total excision & NA & + \\
\hline Heavner et al. [9] & 23 & $\mathrm{~F}$ & Parotid gland & $2 \times 1$ & Low & Total parotidectomy + RT & NED/1y & + \\
\hline Veras et al. [10] & 70 & $\mathrm{~F}$ & Parotid gland & $4 \times 3$ & Low & Superficial parotidectomy & $\begin{array}{l}\text { Dead of other } \\
\text { disease/11y }\end{array}$ & + \\
\hline Veras et al. [10] & 37 & M & Parotid gland & $2.2 \times 1 \times 1$ & Low & Superficial parotidectomy & NED/17y & + \\
\hline Veras et al. [10] & 49 & $\mathrm{~F}$ & Parotid gland & $2.6 \times 1.7$ & Low & Superficial parotidectomy & $\mathrm{NED} / 4 \mathrm{mo}$ & + \\
\hline Veras et al. [10] & 16 & $\mathrm{~F}$ & Parotid gland & $2 \times 2$ & Intermediate & Superficial parotidectomy & $\mathrm{NED} / 10 \mathrm{mo}$ & + \\
\hline Aguiar et al. [11] & 43 & $\mathrm{~F}$ & $\begin{array}{l}\text { Minor salivary glands } \\
\text { (palate) }\end{array}$ & $4 \times 4$ & Low & Partial maxillectomy & NED/19mo & + \\
\hline Shinhar [12] & 57 & $\mathrm{~F}$ & Parotid gland & 2 & Intermediate & Superficial parotidectomy + RT & NED/3y & - \\
\hline Mendelson et al. [13] & 21 & $\mathrm{~F}$ & Parotid gland & 2 & Low & $\begin{array}{l}\text { Total parotidectomy + level-II } \\
\text { neck dissection }\end{array}$ & NED/3y & - \\
\hline Tian et al. [14] & 42 & $\mathrm{~F}$ & Parotid gland & 1.5 & Low & Local excision & $\mathrm{NED} / 19 \mathrm{mo}$ & - \\
\hline Tian et al. [14] & 52 & $\mathrm{~F}$ & Parotid gland & 1.4 & Low & Local excision & $\mathrm{NED} / 31 \mathrm{mo}$ & - \\
\hline Tian et al. [14] & 62 & $\mathrm{~F}$ & Parotid gland & 2 & Low & Local excision & Lost to follow-up & - \\
\hline Tian et al. [14] & 28 & M & Parotid gland & 1.2 & Low & Local excision & NED/8mo & - \\
\hline Tian et al. [14] & 65 & $\mathrm{~F}$ & Parotid gland & 1.5 & Low & Local excision & $\mathrm{NED} / 4 \mathrm{mo}$ & - \\
\hline Tian et al. [14] & 32 & M & Submandibular gland & 1.1 & Low & Local excision & Lost to follow-up & - \\
\hline Tasaki et al. [15] & 79 & M & Submandibular gland & 5.6 & Low & $\begin{array}{l}\text { Total excision of } \\
\text { submandibular gland }\end{array}$ & $\mathrm{NED} / 15 \mathrm{mo}$ & + \\
\hline Current case & 61 & M & $\begin{array}{l}\text { Minor salivary glands } \\
\text { (upper lip) }\end{array}$ & $1.2 \times 0.9$ & Intermediate & Resection & $\begin{array}{l}\text { Local recurrence/ } \\
\text { 30mo }\end{array}$ & + \\
\hline
\end{tabular}

F, female; M, male; mo, month(s); NA, not available; NED, no evidence of disease; RT, radiotherapy; TATE, tumor-associated tissue eosinophilia; y, year(s).

developed lymph node metastasis and one died from pulmonary metastasis [6]. According to our survey of past reports, tumor-associated tissue eosinophilia is not necessarily related to malignancy. In addition, cases in which secondary metastasis occurred had a low grade of malignancy. Although local excision was effective in most cases, our experience suggests that SMECE has invasive characteristics.

Many previous reports have classified tumors with eosinophilic infiltration into carcinomas and lymphomas. In past studies, tissue eosinophils have been suggested to indicate an inflammatory host response against a tumor or to be an eosinophilotactic factor derived from tumor cells themselves; however, the mechanism underlying eosinophilic infiltration remains unclear [18,19]. In addition, reports on the prognosis of tumors with eosinophilic infiltration are inconsistent [20,21]. In some hematopoietic tumors, such as Hodgkin's disease or mucosa-associated lymphoid tissue, lymphoma tissue fibrosis has also been observed [22].

Samoszuk [23] showed that eosinophils stimulate DNA synthesis in fibroblasts, and may be involved in the remodeling of host connective tissue and blood vessels in response to a growing tumor. The tissue sclerosis and venous invasion evident in our case were probably a result of eosinophilic infiltration.

Whether SMECE in the salivary glands represents a distinct tumor type or merely a morphological variant of 
conventional MEC remains controversial [17]. In most cases with thyroid involvement, SMECE occurs in the setting of Hashimoto's thyroiditis. However, consistent with findings from other patients with salivary gland involvement, our patient developed no complications such as Sjögren's syndrome or other autoimmune diseases.

In this case, we resected the tumor with no consideration of the possibility of malignancy and subsequently encountered recurrence three years later. Although it is probable that the secondary tumor originated from residual tumor cells, its growth was slow. It was necessary to perform the second surgery as soon as the diagnosis was made because the surgical margin was close to the tumor.

\section{Conclusion}

We reported a case of local recurrence of SMECE. Our experience with the present case indicates that SMECE can originate in the minor salivary glands and that this rare variant of thyroid carcinoma may be clinically or pathologically misdiagnosed as other conditions, such as inflammatory lesions, benign metaplasia, or different types of malignant tumor with tissue sclerosis. Although the prognosis of SMECE is relatively good according to published reports, we continue to monitor our patient carefully.

\section{Consent}

Written informed consent was obtained from the patient for publication of this case report and accompanying images. A copy of the written consent is available for review by the Editor-in-Chief of this journal.

\section{Abbreviations}

CEA: carcinoembryonic antigen; CT: computed tomography; EMA: epithelial membrane antigen; MEC: mucoepidermoid carcinoma; MIB-1: mindbomb E3 ubiquitin protein ligase 1; SMECE: sclerosing mucoepidermoid carcinoma with eosinophilia.

\section{Competing interests}

The authors declare that they have no competing interests.

\section{Authors' contributions}

YK reviewed the literature and wrote the manuscript. KS and HM investigated the disease concepts and checked the structure of the text. TA performed the surgery and followed up with the patient. MU and MK performed the histopathological diagnoses. All authors read and approved the final manuscript.

\section{Acknowledgments}

We would like to thank our patient for his cooperation and consent for us to use his medical data and photographs for this article.

\section{Author details}

'Department of Oral and Maxillofacial Surgery, Fujita Health University School of Medicine, 1-98 Dengakugakubo, Kutsukake, Toyoake, Aichi Pref, Japan. ${ }^{2}$ Department of Diagnostic Pathology, Fujita Health University School of Medicine, 1-98 Dengakugakubo, Kutsukake, Toyoake, Aichi Pref, Japan.

Received: 30 June 2014 Accepted: 14 January 2015

Published online: 24 February 2015

\section{References}

1. Chan JK, Albores-Saavedra J, Battifora H, Carcangiu ML, Rosai J. Sclerosing mucoepidermoid thyroid carcinoma with eosinophilia: a distinctive lowgrade malignancy arising from the metaplastic follicles of Hashimoto's thyroiditis. Am J Surg Pathol. 1991;15:438-48.

2. Das $S$, Kalyani R. Sclerosing mucoepidermoid carcinoma with eosinophilia of the thyroid. Indian J Pathol Microbiol. 2008;51:34-6.

3. Chan JKC, Saw D. Sclerosing mucoepidermoid tumor of the parotid gland: report of a case. Histopathology. 1987;11:203-7.

4. Muller S, Barnes L, Goodurn Jr WJ. Sclerosing mucoepidermoid carcinoma of the parotid. Oral Surg Oral Med Oral Pathol Oral Radiol Endod. 1997;83:685-90.

5. Sinha SK, Keogh IJ, Russell JD, O'Keane JC. Sclerosing mucoepidermoid carcinoma of minor salivary glands: a case report. Histopathology. 1999;35:283-4

6. Urano M, Abe M, Horibe Y, Kuroda M, Mizoguchi Y, Sakurai K, et al. Sclerosing mucoepidermoid carcinoma with eosinophilia of the salivary glands. Pathol Res Pract. 2002;198:305-10.

7. Fadare O, Hileeto D, Gruddin YL, Mariappan MR. Sclerosing mucoepidermoid carcinoma of the parotid gland. Arch Pathol Lab Med. 2004;128:1046-9.

8. Ide F, Obara K, Enatsu K, Mishima K, Saito I. Sclerosing mucoepidermoid carcinoma of the oral cavity. J Oral Pathol Med. 2005;34:187-9.

9. Heavner SB, Shah RB, Moyer JS. Sclerosing mucoepidermoid carcinoma of the parotid gland. Eur Arch Otorhinolaryngol. 2006;263:955-9.

10. Veras EF, Sturgis E, Luna MA. Sclerosing mucoepidermoid carcinoma of the salivary glands. Ann Diagn Pathol. 2007;11:407-12.

11. Aguiar MC, Bernardes VF, Cardoso SV, Barbosa AA, Mesquita RA, Carmo MA. A rare case of sclerosing mucoepidermoid carcinoma arising in minor salivary glands with immunohistochemical evaluation. Minerva Stomatol. 2008:57:453-7.

12. Shinhar SY. Sclerosing mucoepidermoid carcinoma of the parotid gland: case report. Ear Nose Throat J. 2009;88:E29-31.

13. Mendelson AA, al-Macki K, Chauvin P, Kost KM. Sclerosing mucoepidermoid carcinoma of the salivary gland: Case report and literature review. Ear Nose Throat J. 2010;89:600-3.

14. Tian W, Yakirevich E, Matoso A, Gnepp DR. IgG4(+) plasma cells in sclerosing variant of mucoepidermoid carcinoma. Am J Surg Pathol. 2012;36:973-9.

15. Tasaki T, Matsuyama A, Tabata T, et al. Sclerosing mucoepidermoid carcinoma with eosinophilia of the salivary gland: case report and review of the literature. Pathol Int. 2013;63:125-31.

16. Goode RK, El-Naggar AK. Mucoepidermoid carcinoma. In: Leon B, John WE, Peter R, David S, editors. Pathology and genetics of head and neck tumours (World Health Organization Classification of Tumours). Lyon: IARC Press; 2005. p. 219-20.

17. Cheuk W, Chan JKC. Advances in salivary gland pathology. Histopathology. 2007;51:1-20.

18. Lowe D, Jorizzo J, Hutt MS. Tumour-associated eosinophilia: a review. J Clin Pathol. 1981;34:1343-8.

19. Cormier SA, Taranova AG, Bedient C, Nguyen T, Protheroe C, Pero R, et al. Pivotal advance: eosinophil infiltration of solid tumors is an early and persistent inflammatory host response. J Leukoc Biol. 2006;79:1131-9.

20. Thompson AC, Bradley PJ, Griffin NR. Tumor-associated tissue eosinophilia and long-term prognosis for carcinoma of the larynx. Am J Surg. 1994;168:469-71.

21. Tadbir AA, Ashraf MJ, Sardari Y. Prognostic significance of stromal eosinophilic infiltration in oral squamous cell carcinoma. J Craniofac Surg. 2009;20:287-9.

22. von Wasielewski R, Seth S, Franklin J, Fischer R, Hübner K, Hansmann ML, et al. Tissue eosinophilia correlates strongly with poor prognosis in nodular sclerosing Hodgkin's disease, allowing for known prognostic factors. Blood. 2000;95:1207-13.

23. Samoszuk M. Eosinophils and human cancer. Histol Histopathol. 1997;12:807-12 